\title{
Twenty-four-hour urinary sodium and potassium excretion and associated factors in Japanese secondary school students
}

\begin{abstract}
Masayuki Okuda $^{1}$, Keiko Asakura ${ }^{2,3}$, Satoshi Sasaki ${ }^{3}$ and Keiko Shinozaki ${ }^{1}$
Data on the sodium and potassium intake using dietary records among schoolchildren are sorely lacking in the Japanese literature. Some evidence indicates that sodium and potassium intake has been correctly measured, but information concerning these associated factors is scarce. The 24-h urine samples and first morning voiding (overnight) samples were collected twice from 68 secondary schoolchildren in Suo-Oshima Town, Japan. Sodium, potassium and creatinine concentrations were analyzed. Body height and weight were measured, and menstruation and physical activity were assessed via questionnaires. We analyzed the 24-h samples with a $>20$-h collecting period and no missed voiding. The 24-h sodium excretion was $163.2 \pm 36.8$ and $149.8 \pm 45.1 \mathrm{mmol}$ per $24 \mathrm{~h}$ for the boys and girls, respectively. Considering daily habits and loss from sweat, intake was assumed to be $10.6 \pm 1.2$ and $10.0 \pm 2.4 \mathrm{~g}$ per day for the boys and girls, respectively. The 24-h potassium excretion was $43.4 \pm 10.8$ and $45.8 \pm 14.4 \mathrm{mmol}$ per $24 \mathrm{~h}$ for the boys and girls, respectively. Estimated usual potassium intake was $2195 \pm 401$ and $2330 \pm 630 \mathrm{mg}$ per day for the boys and girls, respectively. Sodium excretion was associated with sodium and potassium concentrations in overnight urine samples and physical activity. Potassium excretion was associated with height and physical activity. We described daily sodium and potassium excretion in Japanese secondary schoolchildren. Excretion was associated more with physical activity than with bodyweight. Therefore, the estimation methods used in adults are not applicable for use in adolescents.
\end{abstract}

Hypertension Research (2016) 39, 524-529; doi:10.1038/hr.2016.24; published online 3 March 2016

Keywords: adolescent; dietary; potassium; sodium; urine specimen collection

\section{INTRODUCTION}

High salt intake is a possible cause of adult hypertension, ${ }^{1}$ cardiovascular diseases ${ }^{2}$ and gastric cancer. ${ }^{3}$ The World Health Organization (WHO) recommends a salt intake $<5 \mathrm{~g}$ per day to decrease blood pressure and reduce the risk of cardiovascular diseases. ${ }^{4}$ In Japan, although dietary salt intake has decreased over the past several decades, it exceeds the Japanese recommendations of $<8.0 \mathrm{~g}$ for men and $<7.0 \mathrm{~g}$ for women, which are higher than the WHO recommendations. ${ }^{5,6}$

In children, dietary salt intake is also related to blood pressure, ${ }^{7}$ and the WHO strongly recommends a low salt intake, as well as a high, energy-based potassium intake to prevent adult hypertension. ${ }^{4}$ Considering the maintenance of similar dietary habits from childhood into adulthood, ${ }^{8}$ it is important to have an adequate understanding of salt intake and to control dietary salt intake from a very young age. However, among Japanese children and adolescents, correct measurements of dietary salt intake using 24-h urinary excretion are scarce. ${ }^{9,10}$ Thirty years ago, Moriyama and Saito ${ }^{9}$ studied 24 -h sodium and potassium excretion in children aged 1-18 years, but the age range was wide, and the variance in excretion increased as the age increased.

One downfall of the 24-h urine collection is the inconvenience it poses for study participants. Because a 24 -h mineral and creatinine excretion is associated with adult height, weight and age, these have been used to estimate daily sodium and potassium excretion. ${ }^{11-14}$ However, it is not known whether these estimation methods are applicable to adolescents whose body size varies depending on their developmental stage. ${ }^{15}$ The fact that 24 -h sodium excretion is associated with energy intake ${ }^{16}$ may also complicate the estimation, and physical activity and maturation are additional potentially related factors.

Understanding sodium and potassium intake in the population, including adolescents, is a public health issue. A simple method of estimating intake could facilitate the development of a health-care program to improve sodium and potassium intake. In this study, we measured the 24-h sodium and potassium excretion in Japanese secondary school students and examined their association with body

${ }^{1}$ Graduate School of Science and Engineering, Yamaguchi University, Ube, Japan; ${ }^{2}$ Interfaculty Initiative in Information Studies, The University of Tokyo, Tokyo, Japan and ${ }^{3}$ School of Public Health, The University of Tokyo, Tokyo, Japan

Correspondence: Professor M Okuda, Graduate School of Science and Engineering, Yamaguchi University, Minami-Kogushi 1-1-1, Ube 755-8505, Japan.

E-mail: okuda@yamaguchi-u.ac.jp

Received 14 September 2015; revised 17 January 2016; accepted 19 January 2016; published online 3 March 2016 
height, weight, age, spot urine mineral concentration, maturation and physical activity.

\section{METHODS}

\section{Subjects}

The subjects were 320 secondary school adolescents (12-15 years) living in SuoOshima Town, Yamaguchi Prefecture, Japan. Out of these 320 students, we recruited 281 students who were attending four municipal secondary schools. After explaining the protocol, we obtained written informed consent from 68 pairs of students and their guardians (Supplementary Figure S1). We gave the participants stationery valued at $¥ 2000$. The protocol was approved by the Institutional Review Board of Yamaguchi University Hospital (H25-87) and the Ethics Committee of the University of Tokyo, Faculty of Medicine (10259). We also explained the study protocol to the Suo-Oshima Town Education Board and each school and waited for their approval before starting the study.

\section{Urine sampling}

Urine sampling was conducted from 23 November 2013 to 10 February 2014. During this period, a 24-h urine sample was collected twice from the 68 participants, and overnight sampling was conducted three times (Supplementary Figure S2). The 24-h urine collections were taken at an interval of $>1$ week between them, and each pair of the three overnight samplings had intervals of $>3$ days between them. Any samplings on the days marked by sickness, menstruation or vigorous sporting events were avoided. Overnight urine was collected in a paper cup upon awakening at the start of the day (a non-school day before a school day), and $7-8 \mathrm{ml}$ of the overnight specimen was stored in a plastic test tube in a cold place. The participants recorded the time of voiding. Because of concerns regarding the noncompliance of the students, such as their mixing overnight urine into the 24-h urine sample or 'mis-sampling' their overnight urine, we chose to have overnight urine sampling taken before the 24-h urine collection.

After this, the 24-h collection was initiated. Every urine voiding was collected into one-liter wide-mouth plastic bottles and was placed in a expanded polystyrene container with refrigerant (As one Corporation, Osaka, Japan). The estimated time and an approximate volume were recorded for missing samples. The last sample was collected the next day by overnight voiding, and the time was recorded.

On the morning of the second day, we gathered stored samples in the expanded polystyrene containers (Ikeda Scientific Co. Ltd., Tokyo, Japan) at each school, mixed the 24-h samples in the bottles from each participant together in a bucket, measured the total volume and refrigerated a $7-8-\mathrm{ml}$ sample of the 24 -h sample in another test tube at $-20^{\circ} \mathrm{C}$, along with the overnight sample until urinalysis. The third overnight sample was collected using the same method without the 24-h collection occurring on the other days.

\section{Urinalysis}

Frozen samples were transferred and analyzed by the LSI Medience Corporation (Tokyo, Japan). Sodium and potassium concentrations $\left(\mathrm{mmol}^{-1}\right)$ were analyzed using the electrode method. Creatinine concentration $\left(\mathrm{mmol} \mathrm{l}^{-1}\right)$ was analyzed using the enzyme test. The amount of 24 -h sodium (24-h Na; mmol per day) and potassium (24-h K; mmol per day) excretion was calculated as follows:

$$
\begin{aligned}
24-\mathrm{h} \mathrm{Na}= & \text { concentration }\left(\mathrm{mmol} \mathrm{l}^{-1}\right) \times \text { urine volume }(\mathrm{ml}) \\
& \times 24(\mathrm{~h}) / \text { collection period }(\mathrm{h}) \\
24-\mathrm{h} \mathrm{K}= & \text { concentration }\left(\mathrm{mmol} \mathrm{l}^{-1}\right) \times \text { urine volume }(\mathrm{ml}) \\
& \times 24(\mathrm{~h}) / \text { collection period }(\mathrm{h})
\end{aligned}
$$

The collection period was the difference between the first and last voiding time during the 24 -h collection.

\section{Body measurements and questionnaires}

Body height and weight were measured while the subjects were clothed only in their underwear by school nurses 2 weeks before the urine sampling was conducted. Height $(\mathrm{cm})$ and weight $(\mathrm{kg})$ was measured to one decimal place, and body mass index was calculated as weight $(\mathrm{kg}) / \mathrm{height}(\mathrm{m})^{2}$.

Student lifestyle questionnaires were completed by the students and their guardians. The development of maturation was assessed by the presence of voice breaks for the boys and menarche for the girls, according to one of the nine options: '<4th grade', each one of 4-9th grades, 'not yet' or 'unknown.' We classified the subjects into one of the two categories: 'immature' for 'not yet' or 'mature' for the other options.

For the physical activity evaluation, the students reported their participation in either vigorous or moderate activity during a usual week in hours and minutes, and they reported their commute time to school (whether walking or riding a bicycle) in minutes. ${ }^{17}$ We calculated the physical activity of the commute per week as one-way $\times 2$ (to and from) $\times 5$ (days per week). Total physical activity (min per week) was the sum of vigorous activity, moderate activity and commuting. Age in months was the difference between the birth date and the date of the first urine sampling.

\section{Statistical analysis}

We analyzed the data from the 24-h samples with a collecting period $>20 \mathrm{~h}$ and with no missed voiding. Continuous variables are expressed as the mean \pm s.d. and categorical variables as counts and percentages. We considered the urinary excretion of sodium and potassium as $86 \%$ and $77 \%$ of intake, respectively, in accordance with Hollbrook et al. ${ }^{18}$ and estimated the usual intake from 2 days' worth of data, according to the Nusser method using PCSide ver.1.0 (CARD, Ames, IA, USA). ${ }^{19}$

The characteristics of the participants and non-participants were examined using either a $t$ or chi-square test. We examined the linear trend for the continuous variables (first overnight urine concentrations of sodium, potassium and creatinine, age, height, weight and total physical activity) and used the Cochran-Armitage test to examine the categorical variables (sex and maturation) among three subgroups, which were classified using tertiles according to their first 24-h sodium or potassium excretion. Factors significantly associated with 24-h excretion were included as explanatory variables in a multivariate linear regression analysis (Model 1). A stepwise method was used for the variable selection (Model 2). Regression coefficients obtained from the data of the first measurement (Model 2) were verified using data from the second measurement. We used the Bland-Altman method to assess individual agreement with the measurements, ${ }^{20}$ a paired $t$-test for population agreement and Pearson's correlation for agreement of an individual place in the population distribution. We used SAS ver. 9.4 software (SAS Institute Japan, Tokyo, Japan) for the analysis and considered $P<0.05$ as significant.

\section{RESULTS}

There were no differences in body height, weight, age in months or total physical activity between the 68 participants (Table 1) and the students in Suo-Oshima Town who did not provide a 24 -h urine collection. The percentage (35\%) of boys among the 68 students was lower than that among the remaining students $(53 \% ; P=0.012)$. The percentage $(80 \%)$ of girls who had reached maturation among the participants was lower than that among the remaining students $(93 \%$; $P=0.040$ ). There were 58 students ( 23 boys and 35 girls) who had

Table 1 Characteristics of the subjects

\begin{tabular}{lcr}
\hline & Boys, N=24 & Girls, N=44 \\
\hline Age in years & $14.0 \pm 0.6$ & $14.1 \pm 0.8$ \\
Age in months & $167.4 \pm 7.4$ & $169.3 \pm 9.7$ \\
Height, cm & $160.2 \pm 7.1$ & $154.7 \pm 6.5$ \\
Weight, kg & $52.2 \pm 13.6$ & $49.7 \pm 9.0$ \\
Body mass index, kg m ${ }^{-2}$ & $20.2 \pm 4.0$ & $20.7 \pm 3.4$ \\
Total physical activity, min per week & $1010 \pm 449$ & $684 \pm 470$ \\
Matured & $18(75 \%)$ & $35(80 \%)$ \\
\hline
\end{tabular}

Values are mean \pm s.d. or frequency (\%). 


\begin{tabular}{|c|c|c|c|c|c|c|}
\hline & \multicolumn{3}{|c|}{ Boys } & \multicolumn{3}{|c|}{ Girls } \\
\hline & First time, $\mathrm{N}=23$ & Second time, $\mathrm{N}=18$ & Both, $\mathrm{N}=18$ & First time, $\mathrm{N}=35$ & Second time, $\mathrm{N}=37$ & Both, $\mathrm{N}=31$ \\
\hline Sodium, mmol $\mathrm{I}^{-1}$ & $131.0 \pm 36.7$ & $131.3 \pm 49.1$ & $128.5 \pm 25.4$ & $132.0 \pm 59.8$ & $134.3 \pm 56.5$ & $130.0 \pm 43.7$ \\
\hline Potassium, mmol $\mathrm{I}^{-1}$ & $42.1 \pm 15.2$ & $39.7 \pm 14.7$ & $39.9 \pm 11.4$ & $44.3 \pm 20.8$ & $40.1 \pm 18.2$ & $42.7 \pm 16.9$ \\
\hline Creatinine, $\mathrm{mmol} \mathrm{I}^{-1}$ & $14.6 . \pm 5.9$ & $13.3 \pm 3.9$ & $13.8 \pm 4.5$ & $15.2 . \pm 6.0$ & $13.4 \pm 6.0$ & $14.2 \pm 5.7$ \\
\hline \multicolumn{7}{|l|}{ 24-h excretion } \\
\hline Sodium, $\mathrm{mmol}$ per $24 \mathrm{~h}$ & $153.4 \pm 46.2$ & $169.6 \pm 57.1$ & $163.2 \pm 36.8$ & $153.1 \pm 51.9$ & $152.1 \pm 54.4$ & $149.8 \pm 45.1$ \\
\hline Potassium, mmol per $24 \mathrm{~h}$ & $41.5 \pm 13.1$ & $44.6 \pm 12.7$ & $43.4 \pm 10.8$ & $45.3 \pm 15.2$ & $44.4 \pm 16.9$ & $45.8 \pm 14.4$ \\
\hline
\end{tabular}

Values are mean \pm s.d.

Table 3 Overnight urine concentrations and characteristics of the subjects among tertiles of 24-h sodium and potassium excretion

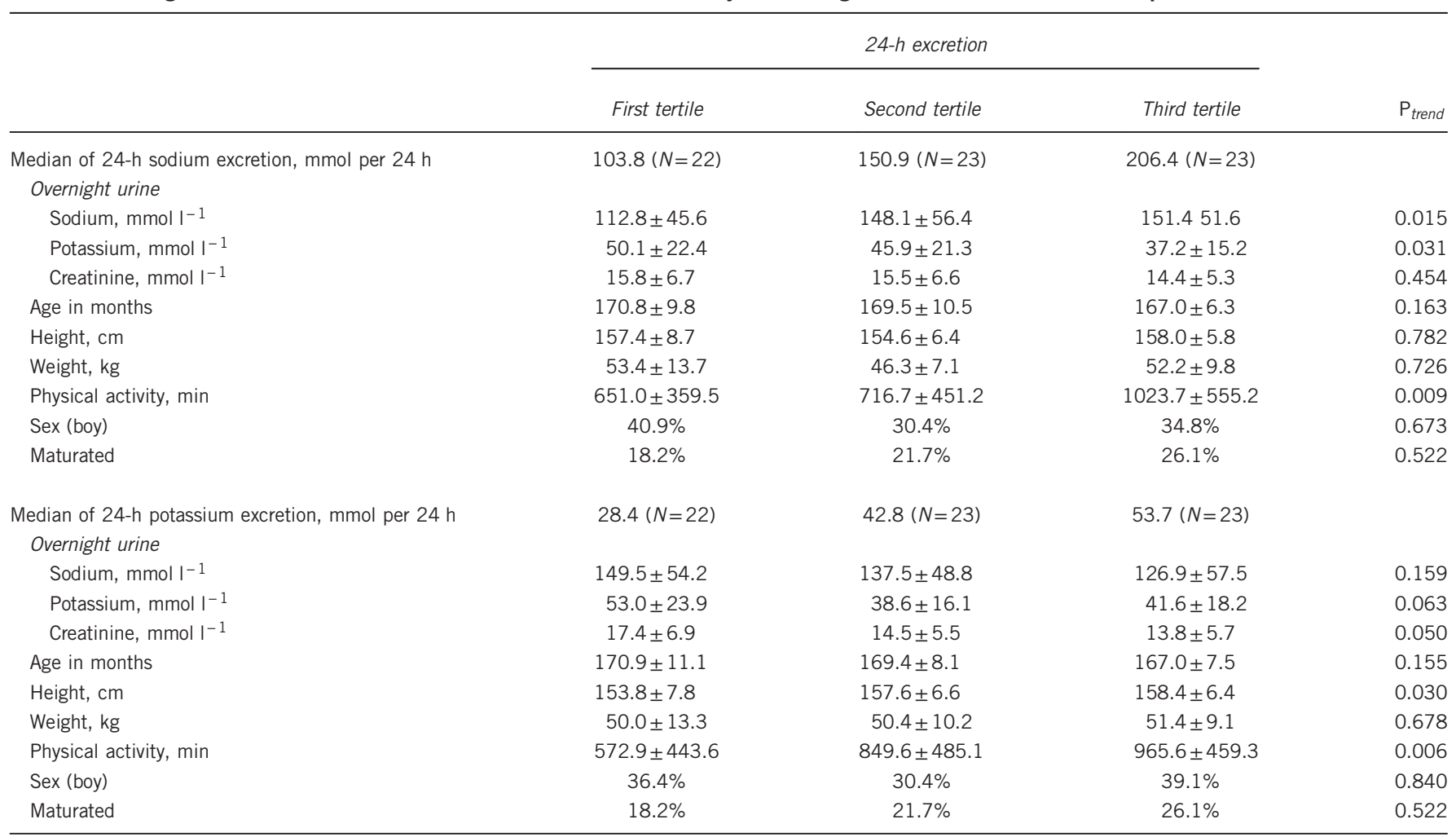

Values are mean \pm s.d. or percentage of the frequency.

$>20 \mathrm{~h}$ and no missing collection data for the first measurement, 55 students ( 18 boys and 37 girls) for the second measurement and 49 students (18 boys and 31 girls) for both measurements (Supplementary Figure S1). These 49 students were no different in terms of characteristics from the 19 students sampling once.

The 24-h excretion was $163.2 \pm 36.8 \mathrm{mmol}$ per $24 \mathrm{~h}$ (equivalent salt: $9.5 \pm 2.2 \mathrm{~g}$ per $24 \mathrm{~h}$ ) and $149.8 \pm 45.1 \mathrm{mmol}$ per $24 \mathrm{~h}$ (equivalent salt: $8.8 \pm 2.7 \mathrm{~g}$ per $24 \mathrm{~h}$; Table 2 ) for the boys and girls, respectively. Estimated usual sodium intake was $10.6 \pm 1.2$ and $10.0 \pm 2.4 \mathrm{~g}$ per day for the boys and girls, respectively (Supplementary Table S1). In addition, $1.8 \%$ of the boys and $10.1 \%$ of the girls satisfied the Japanese references for the 11-14-year-old age group. ${ }^{5}$ The 24 -h potassium excretion was $43.4 \pm 10.8$ and $45.8 \pm 14.4 \mathrm{mmol}$ per $24 \mathrm{~h}$ for the boys and girls, respectively. Estimated usual potassium intake was $2195 \pm 401$ and $2330 \pm 630 \mathrm{mg}$ per day for the boys and girls, respectively, and $15.6 \%$ and $42.3 \%$, respectively, satisfied the references. ${ }^{5}$

Daily sodium excretion was positively associated with overnight urine sodium concentration and physical activity, but it was negatively associated with potassium concentration in both the univariate and multivariate analyses (Table 3 , and Model 1 in Table 4). These variables remained in the model with variable selection (Model 2 in Table 4). Body height, weight or creatinine concentrations were not associated with sodium excretion (Table 3).

Daily potassium excretion was positively associated with body height, physical activity and creatinine concentration in the overnight urine in the univariate analysis, but it was not associated with sodium or potassium concentration in the overnight urine (Table 3). After variable selection in the multivariate model, body height and physical activity remained (Model 2 in Table 4). 
Using Model 2, the 24-h excretion was estimated with the second overnight urine samples. The difference between estimated and measured sodium and potassium excretion was $0.21 \pm 49.96$ $(P=0.976)$ and $-0.24 \pm 14.27 \mathrm{mmol}$ per $24 \mathrm{~h}(P=0.902)$, respectively. Pearson's correlation coefficients were $0.439(P=0.001$; boys, $0.312, P=0.222$; girls, $0.478, P=0.003)$ and $0.403(P=0.002$; boys, $0.168, P=0.505$; girls, $0.534, P=0.001$ ), respectively. Both of the Blond-Altman plots revealed a proportional bias showing that estimation was positive in the low range and negative in the high range (Figure 1). The Blond-Altman plots for both sexes almost overlapped.

\section{DISCUSSION}

In this study, usual salt intake was higher than the Japanese references, but it was similar to or slightly lower than that of a previous report for Nagasaki City, the Northern Kyushu region in 1985, in which the 24-h excretion for 13-15-year-olds was $11.4 \pm 2.4 \mathrm{~g}$ for boys $(N=14)$ and

Table 4 Regression models of 24 -h sodium and potassium excretion (mmol per $24 \mathrm{~h}$ )

\begin{tabular}{|c|c|c|c|c|c|c|}
\hline & \multicolumn{3}{|c|}{$\begin{array}{l}\text { Multivariate model } \\
\text { (Model 1) }\end{array}$} & \multicolumn{3}{|c|}{$\begin{array}{c}\text { Multivariate model after } \\
\text { variable selection (Model 2) }\end{array}$} \\
\hline & $\beta$ & s.e. & $P$-value & $\beta$ & s.e. & $P$-value \\
\hline \multicolumn{7}{|l|}{ Sodium excretion } \\
\hline Intercept & 131.713 & 25.049 & $<.0001$ & 131.713 & 25.049 & $<0.0001$ \\
\hline \multicolumn{7}{|l|}{ Overnight urine } \\
\hline Sodium $\left(\mathrm{mmol} \mathrm{I}^{-1}\right)$ & 0.284 & 0.113 & 0.015 & 0.284 & 0.113 & 0.015 \\
\hline Potassium $\left(\mathrm{mmol} \mathrm{I}^{-1}\right)$ & -0.861 & 0.309 & 0.007 & -0.861 & 0.309 & 0.007 \\
\hline Physical activity (min) & 0.029 & 0.013 & 0.028 & 0.029 & 0.013 & 0.028 \\
\hline \multicolumn{7}{|l|}{ Potassium excretion } \\
\hline Intercept & -64.286 & 48.074 & 0.156 & -62.980 & 44.043 & 0.159 \\
\hline \multicolumn{7}{|l|}{ Overnight urine } \\
\hline Creatinine $\left(\mathrm{mmol} \mathrm{I}^{-1}\right)$ & 0.083 & 0.303 & 0.786 & & & \\
\hline Height $(\mathrm{cm})$ & 0.633 & 0.285 & 0.031 & 0.633 & 0.283 & 0.029 \\
\hline Physical activity (min) & 0.009 & 0.004 & 0.022 & 0.009 & 0.004 & 0.022 \\
\hline
\end{tabular}

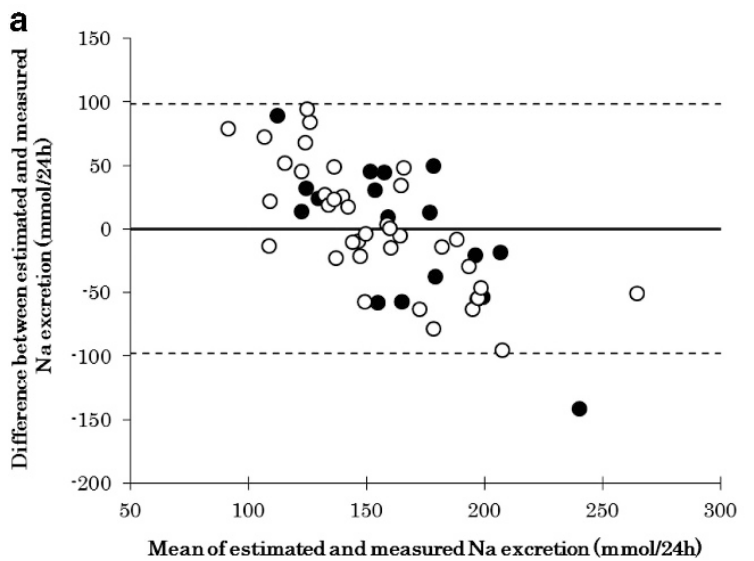

$11.8 \pm 1.7 \mathrm{~g}(N=14)$ for girls. ${ }^{9}$ This study had two measurements of 24-h urine collections and a larger sample size than the previous study. The National Health and Nutrition Survey Japan (NHNSJ) reported that salt intake in adults decreased from $12.2 \mathrm{~g}$ per day in 1985 to $10.0 \mathrm{~g}$ per day in $2012,{ }^{5}$ but salt intake based on a 24 -h urine did not change: $12.7 \mathrm{~g}$ per day in the INTERSALT study ${ }^{21}$ in 1988 , and $12.8 \mathrm{~g}$ per day in the report by Asakura et al. ${ }^{22}$ in 2014. Reduction of salt intake remains a challenge for both Japanese adults and children. The NHNSJ reported that salt intake in the Chugoku region, including Suo-Oshima Town, was less than that in the Northern Kyushu region. ${ }^{5}$ The NHNSJ also reported that the salt intake of girls aged 12-14 years was $1.2 \mathrm{~g}$ lower than that of boys $(9.4 \pm 3.4$ and $10.6 \pm 3.5 \mathrm{~g}$, respectively). The small differences between the sexes, $0.6 \mathrm{~g}$ in this study and $0.4 \mathrm{~g}$ in the previous study, ${ }^{9}$ may indicate underreporting from the girls in the NHNSJ, which relied on dietary records. Urinary excretion, but not dietary records, should be used to estimate salt intake thereby limiting reporting bias.

Physical activity in minutes per week was not correlated with body weight or body mass index in this study (Spearman's correlation: -0.06 to -0.07 ; data not shown), and physical activity (metabolic equivalents) assessed using accelerometers was not significantly associated with body weight or body mass index in another population of secondary school students $\left(-0.21\right.$ to -0.28 ; not published). ${ }^{17}$ Physical activity is one major determinant of energy expenditure. ${ }^{6} \mathrm{~A}$ few reports have indicated that sodium intake is associated with energy intake or expenditure. ${ }^{16,23}$ This may be why physical activity, but not body weight, was related to 24 -h sodium and potassium excretion. Although the variability of sodium and potassium intake in this study may reflect growth, ${ }^{9}$ age and maturation were not associated with excretion. The subjects of this study, only three grades of secondary students, have a narrow range of ages.

Various methods of estimating daily sodium or potassium excretion using spot urine samples have been proposed (in the Supplementary Information) such as the following: (1) direct regression models, ${ }^{14}$ such as the regression coefficients in this study, (2) using the ratio of sodium or potassium to creatinine concentrations and estimated daily creatinine excretion, ${ }^{11-13}$ and (3) using the volume of overnight excretion. ${ }^{24}$ The direct regression methods (1) use body height, body weight or age as parameters, in addition to mineral or creatinine concentrations in spot urine. A negative association between sodium

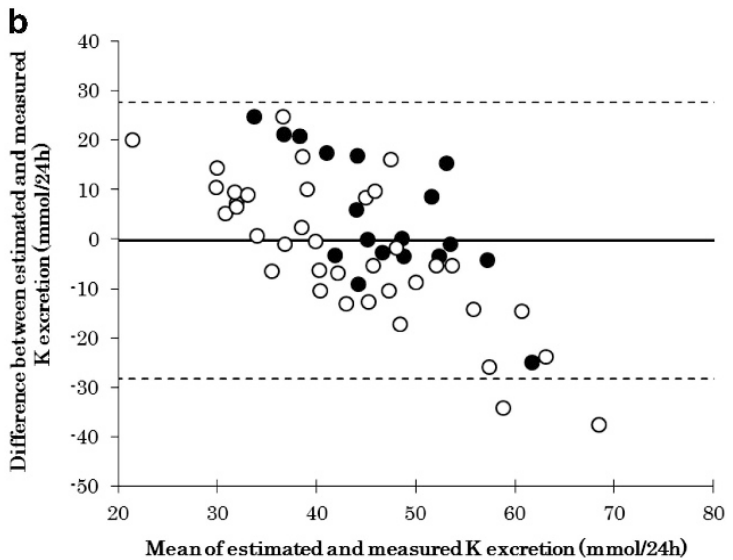

Figure 1 The Bland-Altman plots between the estimated and measured 24-h excretion. Sodium (a) and potassium (b) excretion was estimated using the regression coefficients obtained in Table 4. The horizontal axes indicate the mean values of the estimated and measured excretion. The vertical axes indicate differences between the estimated and the measured excretion. Boys: filled circle; girls: open circle; solid horizontal lines: mean values of the difference; dashed lines: mean \pm 1.96 s.d. 
excretion and potassium concentration in spot urine, as found in this study, was also demonstrated in the regression model proposed by Brown et al. ${ }^{14}$ This could reflect the fact that higher potassium concentrations are indicative of a 'healthier' diet richer in fruit and vegetables and lower in salt. ${ }^{14,25}$

Using the methods (2) proposed by Kawasaki et al., ${ }^{11}$ Tanaka et al. ${ }^{12}$ and Mage et al. ${ }^{13,26}$ to estimate adult excretion in Asian or child excretion in non-Asian ethnic groups, Pearson's correlation coefficients for the subjects in this study were $0.012-0.342$ for sodium, and from -0.219 to 0.249 for potassium (Supplementary Table S2). These methods use estimated creatinine excretion to calculate sodium excretion. In the Mage method of estimating creatinine excretion, ${ }^{13,24}$ body weight is not included as a variable for children or adolescents but is included for adults. The difficulty in estimating creatinine excretion in adolescents invalidates using the methods applied to adults or younger subjects, even though their body weights are not much different from those of adults. If daily creatinine excretion can be correctly estimated among students and physical activity is implicated in the models, these methods would be useful.

Only the last method (3) was used for children and adolescents, on the basis that the amount of sodium in the spot urine correlated with that in the 24-h urine collection. ${ }^{27,28}$ However, because sodium concentration in the overnight urine is lower than that in the 24-h collection, estimated sodium excretion was prone to be underestimated. ${ }^{27,29}$ Although all the secondary school students brought overnight urine samples to school once a year according to the Japanese School Health and Safety Law, the volume of overnight voiding is not recorded. Therefore, the last method was not practical.

The estimated 24-h excretion using the second overnight urine sample was similar to the second measured 24-h excretion. The second overnight urine sample may not have been identical to the first sample because day-to-day variability in sodium intake is relatively large. ${ }^{30-32}$ Therefore, it is possible to estimate average population sodium excretion using the regression coefficients obtained in this study. Even with a potential proportional bias in individual estimates of excretion among students as observed in the estimations for adults, ${ }^{27}$ a moderate correlation between individual values was obtained. External validation will be necessary in the future.

The sampling of overnight urine and the 24-h collection of voiding were continuous, but the 24 -h sample did not include the overnight sample, which may result in a low estimation accuracy. The half-life of sodium excretion in humans is approximately $24 \mathrm{~h}^{33}$ Therefore, sodium in 24-h urine taken from Sunday to Monday may reflect mostly dietary intake on Sunday, but sodium in overnight urine on Sunday may mostly reflect Saturday's dietary intake. It is necessary to obtain overnight urine samples just after the 24-h urine collection to confirm the validity of the estimation methods.

Correlation coefficients between the estimated and measured excretion, using a single formula without distinction between the sexes, were lower in the boys than the girls. There were less boy participants than that of the girls, even though the Bland-Altman plots for both sexes overlapped.

Some other limitations are present in applying the results of this study. We obtained detailed data, for example, urine samples were taken twice, and written records were made of voiding times. However, the number of subjects and the area in which the subjects lived were relatively small, and there was the possibility that they could have forgotten to make their recordings. In addition, the study duration was from November to February and did not include hot summer days. This period included a number of school and cultural events and a variation of temperatures, which may have increased measurement errors. The measured 24-h excretion may not reflect the usual intake because 24-h sampling was conducted on non-school days. The third overnight urine sampling was carried out on schooldays, but sodium and potassium concentrations in the overnight urine were not different among the first, second and third times (data not shown). Some students may forget about or not recognize signs of maturation. The Turner Index would have been a better measure to use, but the schools and students may have shown resistance and hesitated submitting to that degree of evaluation.

This study has important implications. For one, it is feasible to obtain 24-h urine collections from secondary school students and obtain samples twice. We also discovered that unlike the estimation methods used for adults, physical activity is an important determinant of 24-h sodium and potassium excretion. Furthermore, we showed that it was possible to estimate 24-h excretion using overnight urine in secondary school students.

\section{CONFLICT OF INTEREST}

The authors declare no conflict of interest.

\section{ACKNOWLEDGEMENTS}

We greatly appreciate the work of the public health nurses, school principals, and other staff members from Suo-Oshima Town in coordinating schedules and collecting samples. This study was financially supported by the Health Labour Sciences Research Grant (no. H23-Jyunkankitou (seishuu)-ippan-0001).

1 Dickinson HO, Mason JM, Nicolson DJ, Campbell F, Beyer FR, Cook JV, Williams B, Ford GA. Lifestyle interventions to reduce raised blood pressure: a systematic review of randomized controlled trials. J Hypertens 2006; 24: 215-233.

2 Strazzullo P, D'Elia L, Kandala NB, Cappuccio FP. Salt intake, stroke and cardiovascular disease: meta-analysis of prospective studies. BMJ 2009; 339 : b4567.

3 Tsugane S, Sasazuki S, Kobayashi M, Sasaki S. Salt and salted food intake and subsequent risk of gastric cancer among middle-aged Japanese men and women. $\mathrm{Br} \mathrm{J}$ Cancer 2004; 90: 128-134.

4 WHO. Guideline: Sodium Intake for Adults and Children. WHO: Geneva, Switzerland. 2012.

5 Hishida A, Sasaki S (eds). Dietary Reference Intakes for Japanese, 2015. DaiichiShuppan Co. Ltd. Tokyo, Japan, 2014.

6 Ministry of Labour Health and Welfare. The National Health and Nutrition Survey in Japan, 2012. Ministry of Labour Health and Welfare: Tokyo, Japan, 2014.

7 He FJ, MacGregor GA. Importance of salt in determining blood pressure in children: meta-analysis of controlled trials. Hypertension 2006; 48: 861-869.

8 Craigie AM, Lake AA, Kelly SA, Adamson AJ, Mathers JC. Tracking of obesity-related behaviours from childhood to adulthood: a systematic review. Maturitas 2011; 70: 266-284.

9 Moriyama M, Saito $\mathrm{H}$. Twenty four-hour urinary excretion of sodium, potassium and urea in Japanese children. Tohoku J Exp Med 1988; 154: 381-388.

10 Grimes CA, Riddell LJ, Campbell KJ, Nowson CA. Dietary salt intake assessed by $24 \mathrm{~h}$ urinary sodium excretion in Australian schoolchildren aged 5-13 years. Public Health Nutr 2012; 98: 189-196.

11 Kawasaki T, Itoh K, Uezono K, Sasaki H. A simple method for estimating $24 \mathrm{~h}$ urinary sodium and potassium excretion from second morning voiding urine specimen in adults. Clin Exp Pharmacol Physiol 1993; 20: 7-14.

12 Tanaka T, Okamura T, Miura K, Kadowaki T, Ueshima H, Nakagawa H, Hashimoto T. A simple method to estimate populational 24-h urinary sodium and potassium excretion using a casual urine specimen. J Hum Hypertens 2002; 16: 97-103.

13 Mage DT, Allen RH, Kodali A. Creatinine corrections for estimating children's and adult's pesticide intake doses in equilibrium with urinary pesticide and creatinine concentrations. J Expo Sci Environ Epidemiol 2008; 18: 360-368.

14 Brown IJ, Dyer AR, Chan Q, Cogswell ME, Ueshima H, Stamler J, Elliott P, Group IC-OR. Estimating 24-h urinary sodium excretion from casual urinary sodium concentrations in Western populations: the INTERSALT study. Am J Epidemiol 2013; 177: 1180-1192.

15 Cole TJ, Bellizzi MC, Flegal KM, Dietz WH. Establishing a standard definition for child overweight and obesity worldwide: international survey. BMJ 2000; 320: 1240-1243.

16 Zhang J, Temme EHM, Kesteloot $\mathrm{H}$. Alcohol drinkers overreport their energy intake in the BIRNH study: evaluation by 24-h urinary excretion of cations. J Am Coll Nutr 2001; 20: 510-519. 
17 Okuda M, Yoshitake N, Tanaka S, Kunitsugu I, Tan N, Uechi H, Sasaki S, Hobara T. Validity and reliability of physical activity questionnaire for Japanese students. Pediatr Int 2011; 53: 956-963.

18 Holbrook JT, Patterson KY, Bodner JE, Douglas LW, Veillon C, Kelsay JL, Mertz W, Smith JC Jr. Sodium and potassium intake and balance in adults consuming selfselected diets. Am J Clin Nutr 1984; 40: 786-793.

19 Nusser SM, Carriquiry AL, Fuller WA. A semiparametric transformation approach to estimating usual daily intake distributions. J Am Stat Assoc 1996; 91: $1440-1449$.

20 Bland JM, Altman DG. Statistical methods for assessing agreement between two methods of clinical measurement. Lancet 1986; 1: 307-308.

21 Intersalt Cooperative Research Group. Intersalt: an international study of electrolyte excretion and blood pressure. Results for $24 \mathrm{~h}$ urinary sodium and potassium excretion. BMJ 1988; 297: 319-328.

22 Asakura K, Uechi K, Sasaki Y, Masayasu S, Sasaki S. Estimation of sodium and potassium intakes assessed by two $24 \mathrm{~h}$ urine collections in healthy Japanese adults: a nationwide study. Br J Nutr 2014; 112: 1195-1205.

23 Ferdaus SI, Kohno K, Hamano T, Takeda M, Yamasaki M, Isomura M, Shiwaku K, Nabika T. Altitudes of residential areas affect salt intake in a rural area in Japan: a Shimane CoHRE Study. Hypertens Res 2015; 38: 895-898.

24 Dyer AR, Stamler R, Grimm R, Stamler J, Berman R, Gosch FC, Emidy LA, Elmer P, Fishman J, Van Heel N. Do hypertensive patients have a different diurnal pattern of electrolyte excretion? Hypertension 1987; 10: 417-424.

25 Lampe JW. Health effects of vegetables and fruit: assessing mechanisms of action in human experimental studies. Am J Clin Nutr 1999; 70: 475S-490S.

26 Mage DT, Allen RH, Gondy G, Smith W, Barr DB, Needham LL. Estimating pesticide dose from urinary pesticide concentration data by creatinine correction in the Third
National Health and Nutrition Examination Survey (NHANES-III). J Expo Anal Environ Epidemiol 2004; 14: 457-465.

27 Cogswell ME, Wang CY, Chen TC, Pfeiffer CM, Elliott P, Gillespie CD, Carriquiry AL, Sempos CT, Liu K, Perrine CG, Swanson CA, Caldwell KL, Loria CM. Validity of predictive equations for 24-h urinary sodium excretion in adults aged 18-39 y. Am J Clin Nutr 2013; 98: 1502-1513.

28 Brewster L, Bohte E, van Montfrans GA. Systematic review of the use of spot and overnight urine for assessment of sodium excretion. J Hypertens 2010; 28 (e-Supplement A): e230 (Abstract).

29 Iwahori T, Ueshima H, Miyagawa N, Ohgami N, Yamashita H, Ohkubo T, Murakami Y, Shiga T, Miura K. Six random specimens of daytime casual urine on different days are sufficient to estimate daily sodium/potassium ratio in comparison to 7-day 24-h urine collections. Hypertens Res 2014; 37: 765-771.

30 Dyer AR, Shipley M, Elliott P. Urinary electrolyte excretion in $24 \mathrm{~h}$ and blood pressure in the INTERSALT Study. I. Estimates of reliability. The INTERSALT Cooperative Research Group. Am J Epidemiol 1994; 139: 927-939.

31 Wang CY, Cogswell ME, Loria CM, Chen TC, Pfeiffer CM, Swanson CA, Caldwell KL, Perrine CG, Carriquiry AL, Liu K, Sempos CT, Gillespie CD, Burt VL. Urinary excretion of sodium, potassium, and chloride, but not iodine, varies by timing of collection in a 24-hour calibration study. J Nutr 2013; 143 . $1276-1282$.

32 Sakaki M, Tsuchihashi T, Arakawa K, Fukui H, Kameda W, Tominaga M. Long-term variability of urinary salt excretion and blood pressure in hypertensive patients. Hypertens Res 2014; 37: 939-943.

33 Strauss MB, Lamdin E, Smith WP, Bleifer DJ. Surfeit and deficit of sodium; a kinetic concept of sodium excretion. AMA Arch Intern Med 1958; 102 527-536.

Supplementary Information accompanies the paper on Hypertension Research website (http://www.nature.com/hr) 